\title{
School Librarians' Experiences Of Looking At Student Learning
}

\author{
Caroline Wavell \\ Research Assistant \\ Department of Information Management \\ Aberdeen Business School, \\ The Robert Gordon University \\ UNITED KINGDOM
}

\begin{abstract}
This paper discusses a small study in which six secondary school librarians were asked to identify and describe incidents of student learning during or after curriculumrelated, library-based activities. The participants were asked to repeat the exercise after reflecting on potentially relevant research articles, standards and learning frameworks. The study builds upon existing research examining student learning in the school library and explores the connections between student learning and evidence-based practice. The findings are expected to contribute to our understanding of how librarians use indicators of learning and librarians' own learning in relation to the experience of looking at student activity and progress.
\end{abstract}

\section{Research question}

This paper explores a small piece of empirical research conducted with the help of six qualified librarians managing libraries in UK secondary schools (catering for students aged between $11-16$ or 18 years). The research had two distinct but interrelated aims. The first aim was to examine how the participating school librarians describe student learning in the school library context in order to gain greater understanding of indicators that might be used both at the local and wider level to demonstrate the impact of library activities on learning. The second aim was to explore how librarians tackled the task of looking at learning, how they responded to a selection of potentially relevant research articles, literacy and library standards and learning frameworks, and how reflection on this literature influenced further examination of student learning. This second aim provides understanding of how research and guidelines might be practically applied as well as examining the empowering role of evidence-based practice by providing librarians with the opportunity to gain greater understanding of student learning and their role in enhancing effective learning strategies.

Although the intended outcome of the research was a list of indicators which librarians instinctively use when looking at learning, grouped in a manner that could aid a common approach to looking at learning in curriculum support settings, the more significant outcome, as seen from the findings, was an indication of participants' professional learning as they engaged with evidence-based practice and the process of looking at student learning.

The study had recognised limitations. The small number of participants makes generalisations invalid. The short timescale of the study did not allow for meaningful interpretation of changes in librarians' attitude towards or adoption of research findings over time. In addition, student learning experiences are shaped by a number of stakeholders, each of whose understanding of what indicates learning is important to gauge the learning experience as a whole (Williams \& Wavell, 2001). In this research only the librarians" 
perspective is examined. Nevertheless, the findings complement recent research in the USA examining learning from student point of view (Todd \& Kuhlthau, 2004).

\section{Context}

The study is set in a well-established context of advocacy, accountability and selfevaluation, in which the efficiency and value for money of services and effectiveness and impact of those services on users is under scrutiny. Alongside this but less embedded in evaluation culture at the practitioner level is evidence-based practice, described by Todd as using research and professional expertise to make decisions for everyday practice (Todd, 2001). An Australian study of research use in education indicates that those who engage in reflective practice seek out research and become actively involved in generating a network and culture of learning (Figgis, Zubrick, Butorac \& Alderson, 2000). There is valuable literature from around the world to guide and inform school librarians through practical, technological, and conceptual issues facing the profession in the $21^{\text {st }}$ Century. However, there remains a gap between much of the academic conceptual discussion and practitioners' everyday practice.

The research described in this paper arose naturally out of a number of previous studies in which the relationship between student learning and the school library has been explored, and aimed to get closer to what librarians themselves recognised as student learning and how far they feel they could or should look for learning. In the UK, school libraries have a wide variety of persons in charge of resources, while in Scotland the majority of the profession are qualified, if not charteredl, in England the situation is more diverse with some school libraries being managed by qualified or chartered librarians, some by teachers with part-time library responsibilities, others by untrained but often very experienced library assistants, and a few by dual qualified teachers-librarians. While some librarians actively seek an educational role within the school, others are reluctant to develop a role beyond library and resource management (Bentley, 2003). Although not backed by thorough research, there is anecdotal evidence that UK librarians interpret their role as providing literacy support within the school and do not want to undermine their social role with students by being seen as teaching or assessing work. Some of the developments taking place in the US and Australia, where librarians are qualified teachers and expect to take a teaching role, could therefore be seen as less relevant to British school librarians, for example, the idea of information literacy standards and objectives with the potential for assessment. On the other hand these documents do provide guidance on what a school library programme might attempt to incorporate.

In practice, some school librarians in the UK have adopted and adapted information skills models, such as the PLUS (Herring, 1996) and The Big6 (Eisenberg \& Berkowitz, 1990; 2003) models as an extension to traditional library skills, with a few schools attempting to integrate information literacy more fully across the curriculum. An accurate picture of how information literacy (by whatever name) is incorporated into practice in either the library, or indeed the classroom, is not available but there was evidence from the Williams and Wavell study (2001) that participating librarians were not fully aware of international research in, for example, information secking behaviour (Kuhlthau, 1993) or developments in information

I Qualified school librarians have undertaken a first or second degree in library and information studies, while chartered status indicates that work experience by the librarian has been recognised by the national library body, the Chartered Institute of Library and Information Professionals (CILIP). 
literacy standards (e.g. AASL \& AECT, 1998). The developments that have been taking place in the UK library profession as a whole, emphasise access and opportunities to ensure social inclusion (Wavell, Baxter, Johnson \& Williams, 2002) and in school libraries on efficient service and support provision (SOEID/SCCC/SLA/SLIC, 1999; McNicol, 2003). The Museums, Libraries and Archives Council (MLA, formerly Resouree), in collaboration with the Chartered Institute of Library and Information Professionals (CILIP), the School Library Association (SLA) and the Department for Education and Skills (DfES), has also set up a website to encourage advocacy in order to strengthen the educational and financial case for school libraries (www.schoollibrariesadvocicy.co.uk). Again the real issues of effective user outcomes and impact are not fully addressed.

Museums, galleries, public and school libraries all support formal, self-directed and informal learning and the impact of these organisations on learning has attracted recent attention in the UK (Hooper-Greenhill, 2002; Hooper-Greenhill, et al. 2003; Moussouri, 2002: Resource, 2002: Williams \& Wavell, 2001) in an attempt to pull together research and ideas from all these related community sectors. This work has resulted in models for understanding the relationships between providing opportunities for potential learning by creating accessible environments (Resource, 2002; Matarasso, 1997; 1998) and a variety of learning frameworks (Gammon, 2002: McCrory, 2002; MLA, 2004; Williams \& Wavell, 2001). Learning frameworks provide increased understanding of the whole learning experience and have the potential for use as indicators of learning. Identifying appropriate indicators is considered an important part of the evaluation process (Markless \& Streatield, 2000, 2001; Williams \& Wavell, 2001).

In a similar way, information literacy standards provide detailed descriptions of attributes that might be expected of students as they become familiar using a variety of information sources and these could be used as a checklist for the provision of comprehensive and fully integrated information literacy opportunities, have the potential for use as indicators of learning or could be used as an assessment tool. The danger with standards is to view information literacy as a clearly defined linear process when other research has highlighted the complex eyclical nature of the process, influenced by a number of factors operating in each specific information use environment (Dervin, 1992 \& 1997; Kuhlthau, 1993; Moore, 2002; Williams, 1986).

Kuhlthau's research on information seeking behaviour not only highlights the affective dimension of working with information and the cyclical nature of the process but also indicates the importance of timely and appropriate intervention by librarians who understand the process (Kuhlthau, 1993). Limberg, Todd and much of the work conducted in museums and galleries, stress the significance of prior knowledge, understanding and abilities and the purpose for using resources (i.e. the personal agendia) in the knowledge outcomes of individuals (Falk, Moussouri \& Coulson, 1998; Leinhardt, Cowley \& Knutson, 2002; Limberg. 1999; Todd, 1999). Bruce's research also points to the significance of information use in the information experience and has the potential to provide the basis for the provision of opportunities, ensuring that all seven information literacy experiences are provided within any structured library activities programme (Bruce, 1997). An additional factor in determining how students approach activities set by teachers is their pereeption of the task itself, whether students view the information task as an exercise in finding resources, locating facts or interpreting information to justify a point of view (Limberg. 1997; Schroeder \& Zarinnia, 2002) and this is closely linked with students' understanding of the assessment 
criteria (Moore, 1996) and how they perceive teachers value the activity (Williams \& Wavell, 2001).

Findings from research provide librarians with a wide variety of issues worthy of consideration and have the potential to influence the way school librarians and teachers plan activities using library resources, how they support students through the information process and what they look for when evaluating their own contribution to the learning experience. However, the myriad of articles, standards, guidelines, frameworks and rubrics, all of which are intended to help professionals provide both efficient and effective services from the perspective of the user, also has the potential to cause frustration and confusion when busy professionals have little time above their daily duties to seek, select, absorb, synthesise, and apply these models and findings. At the same time there is increasing interest in evidencebased practice as a means of enabling professionals to do just that, because the process of engagement between research and practice provides deeper understanding of what works and why.

\section{Methodology}

A qualitative approach was adopted for this study and purposive sampling was used to identify suitable participants because the most valuable data was expected to be gathered from librarians who were committed to aligning their service provision with effective student learning. During dissemination events and activities following the completion of 'The Impact of the School Library Resource Centre on Learning' study (Williams \& Wavell, 2001) some librarians expressed an interest in the outcomes of the study. Eleven potential participants, interested in looking more closely at opportunities they were providing, were identified in this way and through the active UK electronic discussion list, the School Librarian Network (available at hup:/groups.yahoo.comgroupsin/) and were invited to take part in the study. Six experienced chartered librarians accepted the challenge and all were known to be active in a variety of ways in their own continuing professional development. Four librarians were asked to observe and reflect on information-related, curriculum-based library activities and two were invited to undertake the same exercise with class activities focusing on the promotion of fiction material. These two literacy activities were chosen as being the most commonly recognised support roles which school libraries undertake and because they are likely to provide more tangible learning outcomes than informal or wider personal and social learning, if only because curriculum related activities are expected to have identifiable aims, objectives and outcomes.

The study had four distinct stages:

1. In the first stage, participants were asked to observe a curriculum-based information or reading activity set in the school library and to submit written comments to open questions on how they knew something was learned and what stood out in their mind that made it a good learning experience. These questions were posed by Kuhlthau in the evaluation of the US DeWitt Wallace-Readers Digest Library Power Initiative (Kuhlthau, 1999, p.82). This approach was used in the present study to ensure the librarians themselves took ownership of the research in a way that participants in the Williams and Wavell (2001) case studies were reluctant to do despite interaction with, and encouragement from, the researcher team. Responses from this first task were subject to preliminary analysis using Strauss and Corbin's procedure for open-coding (Strauss and Corbin, 1998). 
2. These responses were then fed back to the participants as part of task two which asked the librarians to read and reflect on each others" responses and a selection of literature set out in an annotated bibliography of potentially relevant articles, frameworks and standards. The material identified in the bibliography was selected as being potentially useful in helping librarians understand the student learning experience and were readily available online. The task did not require in-depth study of all the literature provided but the intervention was intended to stimulate thought and ideas which might influence the way they tackled task three.

3. The third task invited librarians to repeat the exercise of observing similar library activities and, in the light of their reading and reflection, submit written answers to the same two questions.

4. The fourth stage was an informal follow-up interview designed to clarify any comments made during the previous tasks and gave the librarians the chance to summarise their experiences of looking at learning.

The qualitative approach adopted for the research enabled the capture of participating librarians" own accounts of student learning and their own reflections on the literature provided. Each librarian was analysed as a case unit looking at how they described learning. the strategies they used for looking at learning and any changes, adaptations, or reflections prompted by reading material from the annotated bibliography and each others' responses. Each task was then analysed to identify similarities and differences in approach and interests.

All six librarians responded to the first task by submitting their thoughts and observations on student learning and all six were contacted at the end of the project and responded to the informal telephone interview. Five librarians completed tasks two and three.

Preliminary coding of task one data isolated three main categories: learning activity, categorised as active learning, actual learning and strategy. Each data element assigned to a category was capable of supporting one or more dimensions, which qualified the data element in terms of extent, quality or quantity, for example how many pupils were involved, the amount of enthusiasm or depth of understanding. Each data element could also have a context, giving background information which might be used to gauge dimension, for example the expected ability or behaviour of an individual student might be used to gauge the quality of learning for that individual. The dimension and/or context provide a means of determining levels of success but how this is used in practice would depend on how learning is examined at a local level.

The learning activity category included descriptions of engagement with the task in hand, positive affective elements (enthusiasm, concentration) and incorporated processes and practice of skills. Engagement is important, if not essential, for learning to take place. However, there appeared to be a distinction between the learning activity or active learning and what might be termed actual learning, although the distinction between the two was not always elear. Actual learning, as described by the librarians, appeared to be associated with understanding or a desire to extend understanding by pursuing further actions and this involved some form of demonstration to be captured as evidence. such as discussion, articulation, explaining. 
The strategy category included deliberate methods adopted by librarians for looking at learning or supporting the information task and also included more informal opportunities exploited for input or intervention.

When all the responses were subsequently analysed further codes were developed to encompass more fully the idea of the participating librarians as learners and the final coding included the following categories:

- Student learning - indicators and evidence;

- Strategies for identifying learning and challenges encountered;

- Opportunities for learning - activity input, mediation and support:

- Factors limiting learning experiences;

- Librarian reflection or questioning as result of observation or reading material:

- Librarian action as result of observation or reading.

\section{Research findings}

\section{Approaches used to identify student learning}

In response to task 1, some librarians expressed the difficulties they had getting to grips with the first exercise, their uncertainty about what was required or how to make a start. One librarian reflected back on a previous activity, noting perceptions of what took place and using students' completed work to support her decisions about learning. Another librarian planned her approach to observing student learning in advance by considering what she would look for and how and submitted the most detailed response of the group. The others observed the students during the activity and gave examples of learning with evidence to support their decisions. All responses were a mixture of examples of active learning (the immediate activity associated with learning tasks), some actual learning (a demonstration of awareness and understanding) and strategies librarians used both for looking at learning and providing opportunities for learning. Their responses also reflected the differing personal agendas of the participating librarians, their understanding of the requirements of the task, their experience of and commitment to looking at learning and the amount of consideration given before embarking on the exercise. As a result of their differing personal agendas, differences in approaches taken to looking at learning were more marked in task 1 than in task 3 when they had had the chance to assimilate each other's ideas and felt more comfortable with what was required of the tasks.

A variety of methods was used to gather evidenee of learning throughout the tasks but there was one major distinction in strategy between the two tasks, which was influenced by the intervention material. The five librarians who tackled task 3 all attempted to use some form of observation rubric, based on one or other of the learning frameworks. Frameworks and standards were included in the annotated bibliography because this is a route that some international professional bodies are promoting and some individual practitioners find appealing because it can provide some order to the reflection process. The librarians in this study expressed similar needs: "if I could organize my thoughts into a useable tool for recording I would be able to conduct observations more easily" (librarian 1). However, there are also challenges to using these tools which the librarians discovered and not all attempts 
were successful. In practice, one librarian found a rubric detailing particular skills and levels encroached on her freedom to observe the overall learning experience and also restricted her ability to interact naturally at the point of need. Two librarians liked the idea of using a rubric but found it time-consuming and difficult to devise one that satislied their needs. Two other librarians used simple, broad frameworks to focus their attention on areas of learning, such as attitude, skills and cuality of work, and they indicated that this aided their critical reflection.

Responses to task 3 indicated that participants were beginning to reflect on how far it is feasible or how desirable it was for them to assess learning and how any assessment could be used to evaluate their own service provision. There was a general consensus that librarians need to be selective in what monitoring is undertaken at any one time and that it was not possible or desirable to look at learning in too much depth if it detracts from looking at the overall learning experience. There were also concerns expressed about attempting to assess the achievements of individual students which begins to eneroach on the role of a teacher and detracts from the special social role librarians can cultivate with students: "They need to feel they can approach me for help without my making judgements about their ability" (librarian 3). On the other hand, librarians 1 and 5 still expressed their desire to be able to demonstrate the value-added aspects of the library and the library elements of eurriculum work.

In terms of strategies and methods used to gather evidence of learning, librarians complemented intuitive observation (watching, listening, questioning) with more tangible evidence (final product, work in progress, issue statisties) to provide a comprehensive picture of the learning experience. Teacher and pupil feedback, either formal questioning or informal discussion, were also sources of evidence used by the librarians.

\section{Indicators of learning}

Despite differences in the number and variety of indicators identified within the context of the different tasks, there were marked similarities between them; it appeared to be easier for the librarians to identify motivation and skills reflected in learning activities than it is to assess the less tangible knowledge and understanding associated with actual learning. The fact that these were more readily identifiable may reflect the type of data collection methods used for the tasks. However, it may also indicate a lack of mutual understanding and collaboration between teachers and librarians or may reflect the emphasis placed on skills development in learning activities conducted in the library. It may also be that, as librarians become more accustomed to looking at student learning experienees and begin to adjust their strategies accordingly, evidence of independent and creative thinking will become more easily identifiable. When examining the indicators no signifieant difference was detected between those used in reading activities and those used in information activities and, although attempts were made to explore the relationship between the type of tasks undertaken (factfinding or analytical) and the indicators of learning used, the number of variables involved in the study prevented any meaningful conclusions to be made. Although the type of indicators identified in responses to task 1 and 3 were similar, there was a significant difference in the way responses were presented. In the responses to task 3 librarians included a greater number of comments and reflections suggesting they were adopting a more analytical approach to looking at the learning experience as a whole. The responses to task 1 resulted in the identification of predominantly positive aspects of learning, whereas in task 3 there was more reflection on where learning was not as effective as expected. highlighting difficulties encountered by students and areas of limited learning. Librarians were questioning what they considered to be learning, reflecting on the reasons for limited learning and how the 
opportunities and support could be improved to overcome some of the problems. Thus the librarians were engaging with evidence-based practice and developing their own professional learning.

The indicators used by librarians were all context specific and related to the objectives of the particular activities as well as the agenda set by the librarians and teacher. A picklist of such indicators may well serve as a useful point of reference and guide illustrating what might be identified; indeed other librarians expressed appreciation of the comprehensive response to task 1 by librarian 3 in which strategies, indicators and evidence were clearly stated. The indicators used by librarians in this study are also similar to those identified by librarians during the Library Power evaluation (Kuhlthau, 1999) and early indications suggest that professionals in a variety of informal learning environments look for similar things when considering learning. However, the subject of indicators is a complex one and further work is required if they are to be placed in some sort of framework that is meaningful for the aims and objectives of the library and supports curriculum objectives and outcomes, thus contributing to students' academic and social learning. In addition, librarians would need guidance on how to use them to avoid confusions over meaning and the significance of indicators used. For example on occasions, indicators of learning appeared to be confused with quantitative measures of resource use (for example, number of books issued) and strategies for providing learning opportunities and librarians expressed concerns over what indicators meant in terms of actual student learning.

\section{Professional learning: interaction with literature}

All the librarians taking part were known to be familiar with at least some of the literature referenced in the annotated bibliography. Despite this common background, each individual brought to the study differing personal agendas (knowledge, experience, understanding, interests and reasons for agreeing to take part in the study). In this respect the researcher was in a similar position when examining librarian learning in the context of this study as the librarians are when examining student learning in the school library. What the researcher was looking for were indicators that engagement with the literature had taken place and indicators that subsequent decisions or actions were stimulated by the study tasks. The introduction of bibliographic references, although not necessarily changing attitude or practice, did stimulate interest and reflection and aided the decision making process during task 3.

The librarians tackled task 2 in different ways, librarian 2 took a systematic approach working through the majority of references and commenting on their relevance for her practice. During this process she also reflected on her own information process and how this related to her students' use of information. She highlighted four items of action to be incorporated into the re-examination of learning. The other librarians were more selective in what they chose to comment upon. There was however a degree of consensus on what attracted attention.

It was not surprising considering participating librarians' previous knowledge, that the Williams and Wavell impact study attracted attention (Williams \& Wavell, 2001). Other learning frameworks, particularly those suggesting levels of achievement, also struck a cord and the influence of these was seen in how librarians approached task 3 by attempting to use rubrics or frameworks. This suggests that some sort of broad learning framework is valuable as a context within which local indicators and evidence can be set, as well as to focus the 
observation and evaluation. As already stated, the librarians also appreciated the extensive response to task 1 provided by librarian 3 and this reinforces the idea that there is much to be learned from shared experiences. Librarians 2 and 5 were particularly enthusiastic about Kuhlthau's work on the information secking process (Kuhlthau, 1993).

It was apparent from their comments and the manner in which the librarians tackled task 3 that both the exercise and reflection on the bibliographic material had stimulated interest, reflection and action. Librarian 2 discussed how the changes she made had improved her delivery of sessions and enhanced student learning outcomes. Librarians 3 and 4 both indicated that the exereises had helped them make the decision not to look at individual learning in depth but to take an overview approach. Implicit in all the responses was a feeling that the issue of evaluating learning had not been resolved but that they had gained greater understanding of the processes involved.

One of the limitations of the study was that references were more directly related to information activities than reading activities and therefore it may have been less easy for 'reading participants' to relate the documents to their activities. However, other comments also suggest that looking at learning during reading activitics is not an obvious choice or a high priority for some librarians at this stage.

\section{Conclusion}

This small-scale piece of research aimed to examine how school librarians describe student learning before and after exposure to a variety of potentially relevant research and standards documents. A major focus of the study was the type of indicators librarians use as evidence of learning and how these changed, what aspects of the literature attracted interest and how this influenced practice. The methodology was successful in engaging participants with the aims and objectives and resulted in a greater understanding of indicators, some of the challenges associated with interpretation and identification of cognitive learning. As the study progressed, however, it became apparent that the more significant findings were about the relationship between looking at student learning and professional learning, that is, how the whole process of looking closely at student learning. reflecting on observations and taking action to make learning more effective becomes part of evidence-based practice.

The list of indicators identified by librarians covers similar aspects of learning already identified in other studies and did not substantially change as a result of exposure to the literature. Although librarians appreciated the opportunity to confirm their choice of indicators with those identified by others, their actual selection appeared to have been prompted, quite correctly, by the nature and objectives of a particular activity and methods for collecting data. There are challenges in ensuring that indicators do represent what is intended and there was general uncertainty over what indicates actual learning and how cognitive learning, in terms of subject understanding and increased knowledge, can be captured or, indeed, whether it should be captured by librarians. The participants recognised the value of focusing attention on particular aspects of learning when looking for evidence and some indicated the need to link this more closely with activity objectives. Librarians' use of observation rubrics suggests that these can provide a focus for observation but need to be kept simple providing an overview of motivation and engagement with the task in hand and the type of skills being developed. 
The use of indicators of motivation during library activities establishes whether students have engaged with the activity and this can be seen as a prerequisite for learning to take place. Close attention to motivational indicators can also highlight areas of difficulty and the need for mediation or intervention either immediately on an individual basis at the point of need, or for further class development built into the activity structure and delivery.

Progression in terms of specific library and information related skills development is relatively easily identified during library sessions. Knowledge and understanding is more difficult to identify and may require more detailed questioning of students, examination of their strategies or work. It is likely that challenges of establishing causality will limit the extent to which longer-term knowledge gain can be captured in the library setting. However, in order to establish the value of library related activities it would seem important to be able to establish progress not only in information literacy skills but also academic achievement through close collaboration with teaching staff and self-reporting by students. Two librarians indicated that the final outcome of activities observed was improved with changes made to the learning environment. It may well be that the most practical method of looking at progression is by monitoring skills development in the library setting and gathering evidence of the quality of final outcome over time from teaching colleagues, but both need to be underpinned with appropriate indicators, as yet not fully resolved. The use of taxonomies during educational evaluation has been questioned by Wolf (1987) and further research and discussion is needed to establish the relationship between indicators, observation rubrics and monitoring of student learning and linking this to activity objectives and outcomes.

There was general consensus that looking at learning is essential but that librarians have a unique and distinctive role supporting both the academic and social aspects of an individual's development which should not be compromised by taking an assessment route and librarian 2 consciously used the term 'monitoring learning' to make this distinction. However, the issue of assessing or monitoring learning is closely related to making judgements about when and how to intervene and librarians in this study appeared to be comfortable with aiding the learning process through individual and group support. Could this suggest that the participating librarians are implicitly distinguishing between formative and summative assessment but that this is not an explicit part of the teaching/learning culture in the school library setting?

It was evident from the study that actively looking at learning stimulates awareness and reflection of professional practice. One of the major differences between the two monitoring exercises was the increased constructive evaluation of the whole learning environment in response to task 3, when librarians looked at the opportunities, support and mediation provided and the learning taking place or difficulties that students encountered. This was partially influenced by their reading but also by increased understanding as librarians become more aware of the issues and began to interpret what they saw and make decisions about future actions, thus becoming actively involved in evidence-based practice and their own professional learning.

Just as students using the library come with differing experiences, knowledge and understanding so the participating librarians, although all professionally qualified, also approached this study with different personal agendas and contexts in which they work. Their personal interest in learning, their need to demonstrate impact and perceived status within the school all appeared to influence their approach to looking at learning. The immediate interaction and engagement with the study was taken as an indicator of motivation and interest. Conceptual use of research was indicated by questioning of literature in relation to 
practice and instrumental use of research was indicated by stated action plans and reports of decision-making. This reflection on evidence from research and action was seen to begin an iterative process of action, understanding, reviewing, revision and modified action and contributes to the whole process of professional learning. In addition, the majority of participants indicated that taking part in this study had been stimulating. The extent to which personal agenda and background rather than professional qualifications determine the direction and involvement with evidence-based practice would make an interesting future study.

\section{References}

AASL \& Al:('T (1998). Information Pow'er: Building Pantmerships for Le'oning. ('hicago: American Library Association.

Bentley, E. (2003). The value of a school librarian UK viewpoints. Knowledge (Gue'st on the ll'b, 32|2|. [Online] Available from

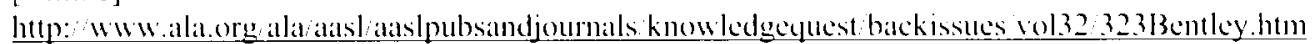
[Accessed 10-(02-(04]

Bruce, (. (1997). The Seren Faces of Information Literact: Adelaide: Auslib.

Dervin, B. (1992). From the Mind's Eye of the User: The Sense-making Qualitative-Quantitative Methodology. In: (jlazier, J.D., \& Powell, R.R. (eds.) Qualitative Re'search in Information Mamagement. Englewood, Colorado: Libraries Unlimited, Inc.. 61-83.

Dervin, B. (1997). (iiven a context by any other name: methodological tools for taming the unruly beast. In: Vakkari, P.. Savolainen, R., \& Dervin, B. (eds.) Information Seching in (ontewt. l.ondon: Taylor (iraham, 1,3-38.

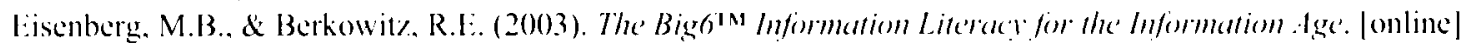
New York: Big6 Associates. Available from hltp: Hww high.com [Accessed 19-(1)3-(04]

Eisenberg. M.B.. \& Berkowitz. R.E. (1990). Information probhem-soling: the Big Sir skills approach to lihrany (m) information. Norwood, NI: Ablex.

Falk, J.. Moussouri, T., \& (oulson, D) (1998). The effect of visitors" agendas on muscum karning. (arrater. $41(2) .106-120$

Figgis, J., Zubrick. A.. Butorac, A., \& Alderson. A. (2000)). Backtracking practice and policies to rescarch. In: Department of Education Training and Youth Affairs lligher Leducation Division, (ed.) The Impact of

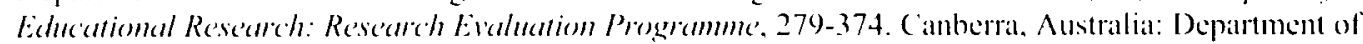
Education Training and Youth Affairs Higher Education Division.

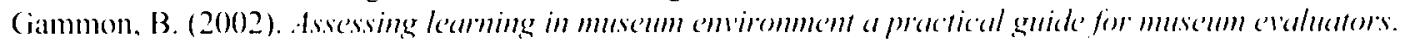
Draft unpublished report for Science Museum. London: Science Museum.

Kuhlthau, (C. C (1993). Implementing a process Approach to Information Skills: A study identifying indicators of success in library media programs. [online] American Library Association. School Lilherer Media

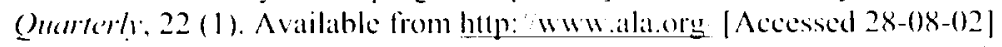

Kuhlthau, C.C. (1999). Student Learning in the Library: What Library Power librarians Say. Schos) Libraries Horldwide. 5(2), 80-96.

Herring. J.1: (1996). Texehing information skills in sichools. London: Library Association.

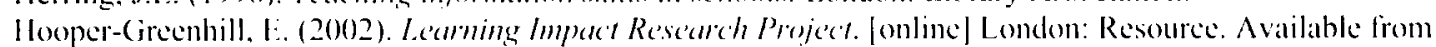
htep www mla.gon uk action learnace lirp.asp [Accessed 02-(03-(1)4]

Hooper-(ireenhill. L.. Dodd. J., Moussouri, T., Jones, C., Pickford. C.. Hermant. ('.. Morrison. M.. Vincent, J., \&

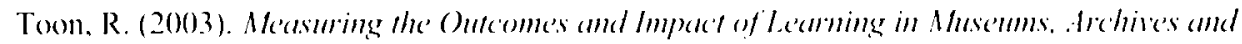
Lithraries. The Learning Impact Research Project End of Project Paper. [online| Leicester: Research Centre for Muscums and (ialleries, University of leciesster. Available from

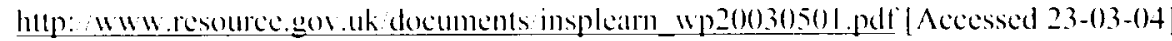

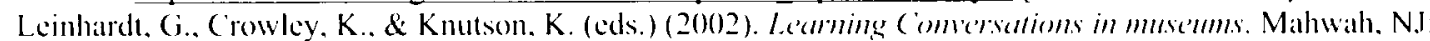
Lawrence Erlbaum Associates.

Limberg, L. (1999). Lxperiencing information secking and learning: a study of the interation between two phenomena. [online] Information Resectrch, 5(1). Available from hitp: inlomationt net ir 51 paperos.him| |Accessed 28-10-013]

Limberg. L. (1997). Information Use for Learning Purposes. In: Vakkari. P.. Savolainen. R. \& Dervin. B. (eds.) Information Secking in comeat. London: Taylor (iraham, 275-289. 
Markless, S., \& Streatficld, D. (2000). The Really Effective College Lihray. London: Information Management Associates for the Library and Information Commission.

Markless, S., \& Streattield, D. (2001). Developing performance and impact indicators and targets in public and education libraries. Intermational Jommal of Information Management, 21, 167-179.

Matarasso, F. (1998). Le'enning development: an introduction to the soc jal impest of public librerices. Bournes Green: Comedia.

Matarasso, F. (1997). Usc or ormament? The soc ial impact of participation in the arts. [online] Bournes (ireen:

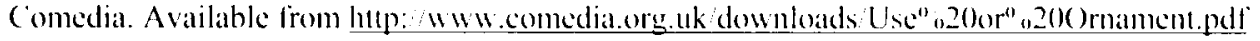
[Accessed Nowember 2003]

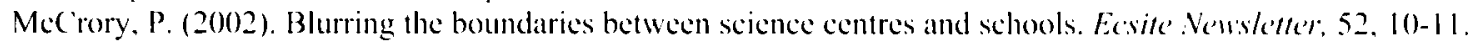

MeNicol, S., \& Etkin. J. (2003). School Lihraries: The Design of a Medel for Self-evaluation. Birmingham: Centre for Information Research. University of (entral England for Resource: The Council for Museums, Archives and Libraries.

Moore. P. (1996). Information Literacy: The importance of questions. [online] Scan. 15(1). Available from hup: WwW.schools.nsw.edu.alu schoollibraries scan 15_1990 moore.hum [Accessed 29-09-03]

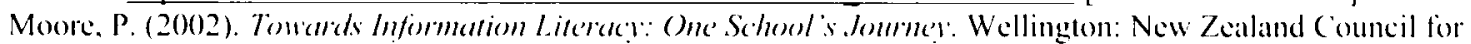
liducational Research.

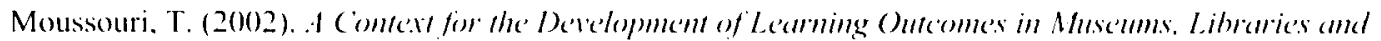
Archines. [online] London: Resource. Available from http www. mla.gow.uk action learnace limp asp] [Accessed (02-(03-()4]

MLA (2004). Inspiring le'arning for all. [online] London: Museums Libraries and Archives (ouncil. Available from http wiw inspiringleamingforall.gov.uk [Acessed 22-03-(1)4]

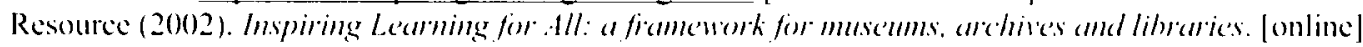
London: Resource. Available from: htep www. resourcegor ak atetion learnate insplearn.pdt [Accessed February 2003]

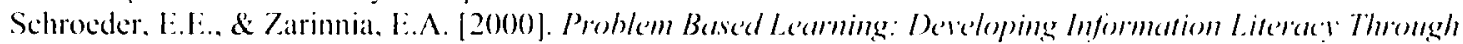
Solving Real Horld Problems. Treasure Me Online. [Restricted access]

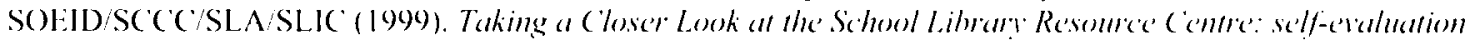

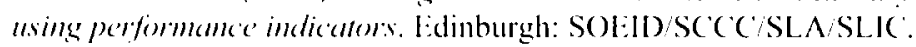

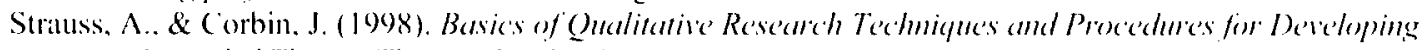
Gromeded Therery. Thousand Oaks: Sage.

Todd. R..I. (1999). Back to our beginnings: information utilization, Bertram Brookes and the fundamental equation of information science. Infermation P'recessing \& Memage'me'm1, 35. 851-870.

Todd. R.J. (2001). Evidence based practice: the sustainable future for teacher-libarians. [online] Sctun. 20(1).

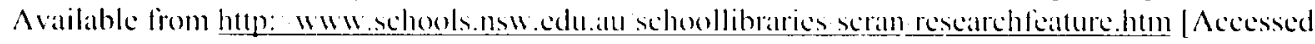
January 2004$]$

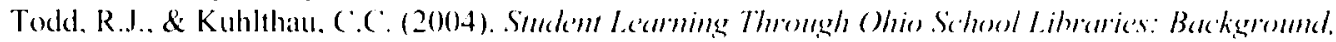
methodologr and report of findings. [online] Ohio Lducational Library Media Association (OELMA).

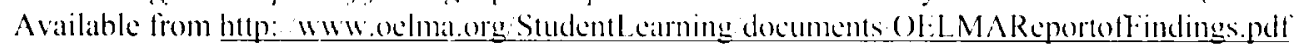
[Aceessed 22-(0)3-()4]

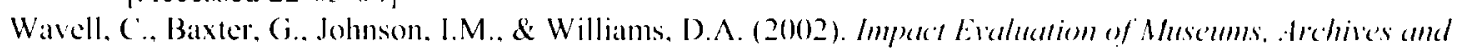

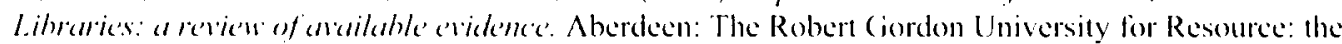
Council for Museums. Archives and Libraries.

Williams, D.A. (1986). The microcomputer in the school libraty. Librong Re've'w, 35(4). 220-230.

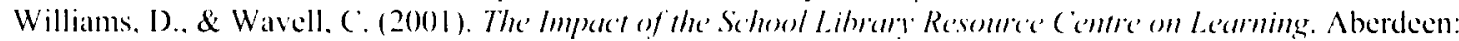
The Robert (iordon University for Resource: The Council for Museums, Archives and Libraries.

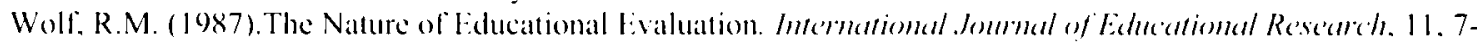
19.

\section{Author Note:}

Caroline Wavell is a Research Assistant working with Professor Dorothy Williams in the Department of Information Management at The Robert Gordon University, Aberdeen. Caroline has been involved in a number of projects exploring the impact on learning of school libraries and other organisations which support informal, self-directed and formal learning. 